\title{
Data-Dependent Acquisition
}

National Cancer Institute

\section{Source}

National Cancer Institute. Data-Dependent Acquisition. NCI Thesaurus. Code C161785.

A method for collecting tandem mass spectrometry data where the $\mathrm{m} / \mathrm{z}$ values are prerecorded for a fixed number of precursor ions followed by a second stage of mass spectrometry and $\mathrm{m} / \mathrm{z}$ analysis. 